\title{
0022 POSITIVE AND NEGATIVE ASPECTS THROUGH ADOLESCENT WORKERS PERSPECTIVE
}

C A Silveira*, M L do Carmo Cruz Robazzi, L A Alves, S M Alves de Paiva, R A Oliveira Correspondence: Pontifical Catholic University of Minas Gerais, Av Padre Francis Cletus Cox, 1661 Poos de Caldas, MG, CEP 37701-355, Brazil

\subsection{6/ip.2010.029215.22}

This study aimed to identify the repercussions of work in adolescents life in a city in the interior of Minas Gerais (Brazil), according to workers perspective. It is a quantitative and qualitative study, using descriptive statistics and content analysis. Subjects were 66 adolescents and results showed a family composition with an average of five people and family income from one to three minimum wages; 27 (40.91\%) of them have field works and $39(59.09 \%)$ work in administrative sectors of different institutions. Regarding time of work, 24 (36.36\%) had worked from 7 to 12 months. Nine (13.64\%) adolescents mentioned having Occupational Accidents and four (6.06\%) have already been taken ill because of work. Financial independence, family help and personal and professional valuation were the categories attributed to the meaning of work. The positive repercussions were development of social and communicative abilities, personal, physical and intellectual development, independence and liberty, to occupy the spare time and improvement in living conditions. The negative repercussions included as follows: tiredness, preoccupation, loss of time spent with family and friends, occupational risks and lack of time for study and leisure. Three thematic categories emerged from the opinion of the families about the occupational condition: support, financial aspect and opportunity. It is concluded that 
the adolescent has a positive view of work, attributing different meanings to it, family also have this viewpoint, even recognising the interferences of work in adolescents life. 